\title{
Media Literacy
}

\section{Connie Nugent MLS, Gilbert Berdine MD}

The purpose of advertising is to create brand recognition and to persuade people to purchase a particular product. If consumers regard a product supplied by two producers as equal in every aspect, the consumers will buy the product with the lowest price. Producers use advertising to suggest that the consumer should prefer the name brand to some other brand and, therefore, pay a price premium for the name brand.

Advertisers use a variety of techniques to convince a person that he or she MUST have this detergent, this car, this snack, this cigarette. Mick Jagger croons in the iconic song, Satisfaction, "When I'm driving in my car/and that man comes on the radio/He's tellin' me more and more/about some useless information/ supposed to fire my imagination."1 Some advertisers make claims that their product is superior to the competition, "When I'm watchin' my TV/and a man comes on and tells me/how white my shirts can be."1 Other advertising is not about the product at all, but rather uses emotion to suggest that the product will magically improve one's life. Flattery, repetition, fear mongering, humor, and powerful words and imagery are useful in arousing a viewer or reader's emotions; the consumer subconsciously transfers this emotional response from the symbol of a desired lifestyle to the product. ${ }^{2} \mathrm{~A}$ young man watching a Harley-Davidson commercial imagines himself as that virile Adonis, roaring down the highway, oblivious to the statistics regarding the safety of motorcycle riding. Consumers need to be aware of these propaganda techniques so

Corresponding author: Connie Nugent Contact Information: Connie.nugent1@gmail.com. DOI: 10.12746/swrccc.v6i25.489

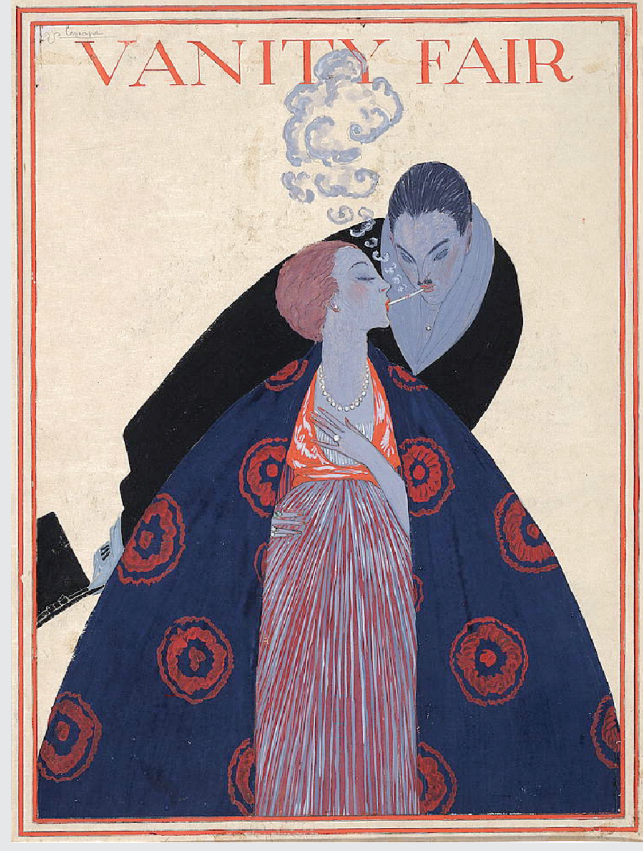

Figure 1. Georges Lepape (1887-1971) Vanity Fair cover December 1919.

Exhibited at "American Beauties: Drawings from the Golden Age of Illustration." Swann Gallery, Library of Congress, 2002.

https://commons.wikimedia.org/wiki/Category: Smoking_women_in_art\#/media/File:Vanity_Fair_ cover_by_Georges_Lepape_1919.jpg

they can make decisions based on facts rather than on emotions. Media literacy is a must.

Cigarette advertising has been wildly successful in luring young people to smoke or to use other forms of tobacco. A 1919 Vanity Fair magazine cover may not be a paid advertisement, but it tacitly supports smoking as an elegant activity (Figure 1). A fashionably dressed woman stands, eyes closed, with her 


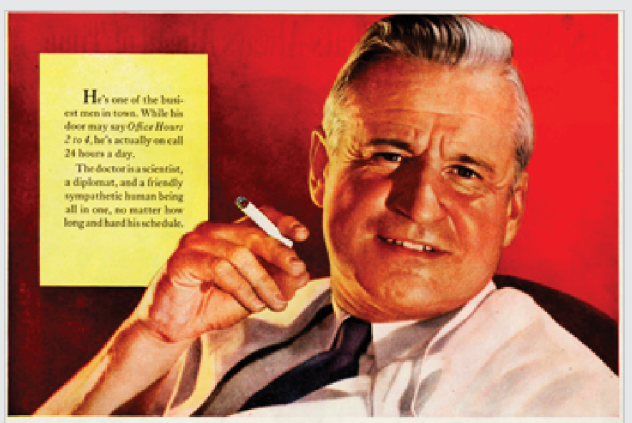

MORE DOCTORS SMOKE CAMELS THAN ANY OTHER CIGARETTE

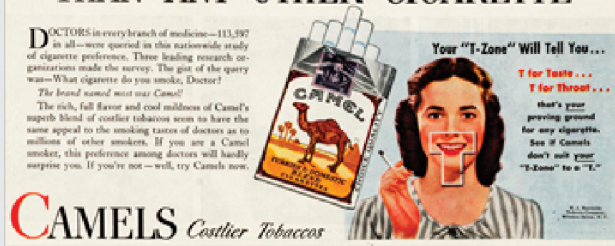

Figure 2. https://www.nytimes.com/2008/10/07/ business/media/07adco.html

head tilted back as an equally fashionably dressed man behind her leans forward. Each smokes a cigarette; the tips of their cigarettes touch, releasing small clouds of smoke that drift upward. The emotional impact is obvious; smoking is alluring. Deconstructing this image requires critical thinking skills, exactly the opposite of the image's goal.

The woman is dressed in high fashion; her cloak billows around her, its purple hue suggesting wealth and royalty. The red flowers echo the colors in her certainly expensive Art Deco pleated dress. Her left hand coyly rests above her low cut bodice and sports a large diamond on her ring finger. A strand of pearls drapes around her throat as she leans toward the taller man, her face turned sideways. Leaning forward, he is wearing a dark topcoat with a lush scarf around the collar and is holding a top hat in his gloved hand. Both sport similar hairstyles and soft makeup. The message is simple-people viewing this magazine cover will associate smoking with elegance, with wealth and beauty, with romance. They will hardly consider the harsh taste and smell of the cigarette smoke as it seeps into hair and clothes and sours the breath.
Cigarette advertising has a long history of associating a desirable lifestyle with smoking a particular brand. As Mick Jagger sang, "Well he can't be a man cause he doesn't smoke/the same cigarettes as me." In the United States, early cigarette advertising contained inches of text explaining the benefits of tobacco or providing testimonials from famous people. RJ Reynolds Tobacco Company claimed that doctors preferred Camels to all other cigarette brands in its 1946 advertising campaign (Figure 2). In this testimonial, a man with just the right amount of gray hair dressed in a doctor's white jacket holds a cigarette as he smiles at the viewer. The text explains why the medical profession prefers Camels; if you can't trust your doctor, whom can you trust?

The Philip Morris Company, now Altria, developed an advertising campaign for its filtered cigarettes that featured rugged cowboys. The Marlboro Man was used to advertise Marlboro cigarettes from 19541999. Deconstructing a typical Marlboro ad reveals its emotional appeal to young men, epitomizing the ultimate in masculinity (Figure 3 ).

A man in close-up looks out of the left side of the ad toward the viewer. He's tanned with some wrinkles around the eyes, which are partially shaded by a large cowboy hat. He sports a walrus mustache and carries a partially smoked cigarette in the right side of

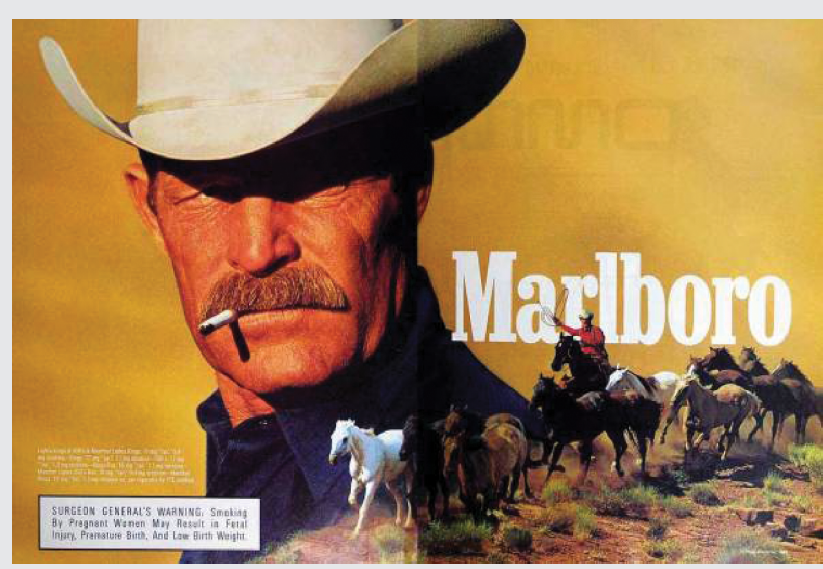

Figure 3. The Marlboro Man.

https://adprinciples.wordpress.com/2013/04/18/ marlboro-man/ posted April 18, 2013 
his unsmiling mouth. This man means business. On the lower right side of the ad is a smaller version of the same cowboy herding horses. He's circling a lariat in his raised right arm as the horses thunder across the sparse landscape. He partially obscures the large white "Marlboro" logo behind him. The background color of the ad is brownish-gold, presumably sunlight but coincidentally the same color of tobacco stains. The required surgeon-general's warning label is in a box in the lower left side of the ad; other warning information above the box is barely visible against the gold background. The Marlboro Man advertisements demonstrated that images were more emotionally powerful than the inches of text included in previous ad campaigns.

Marketing companies are full of smart, talented people. Millions of dollars are spent on advertising, as the Media Literacy Project speculates, “...you cannot spend as much time and effort in deconstruction as the ad agency spent on constructing the ad." 2 The emotional impact of the Marlboro Man campaign resulted in an immediate increase in sales of Marlboro cigarettes worldwide. The campaign ended in the early 2000 s, perhaps due to anti-smoking pressure groups and the smokingrelated deaths of several of the Marlboro cowboys reported in a scathing documentary "Death in the West", ${ }^{3}$ but the iconic image of the rugged Marlboro Man continues. Food Network television personality Ree Drummond, for example, refers to her cowboy/rancher husband as "Marlboro Man" even though he doesn't use tobacco, and her viewers know exactly what she means. ${ }^{4}$

But why should men have all the fun? In 1968 Philip Morris began an advertising campaign specifically targeting girls and women. Couched in language and images that encourage liberation and independence, the "You've come a long way, baby" ads for Virginia Slims cigarettes resulted in a $110 \%$ increase of initiation of smoking by twelve-year-old girls within six years. ${ }^{5}$ Taking advantage of the burgeoning Women's Liberation Movement and society's obsession with thinness, the ads touted Virginia Slims as empowering women, even ironically to sponsoring a tennis tournament. Surely smoking couldn't hurt an athlete! While the Marlboro Men ads portrayed men

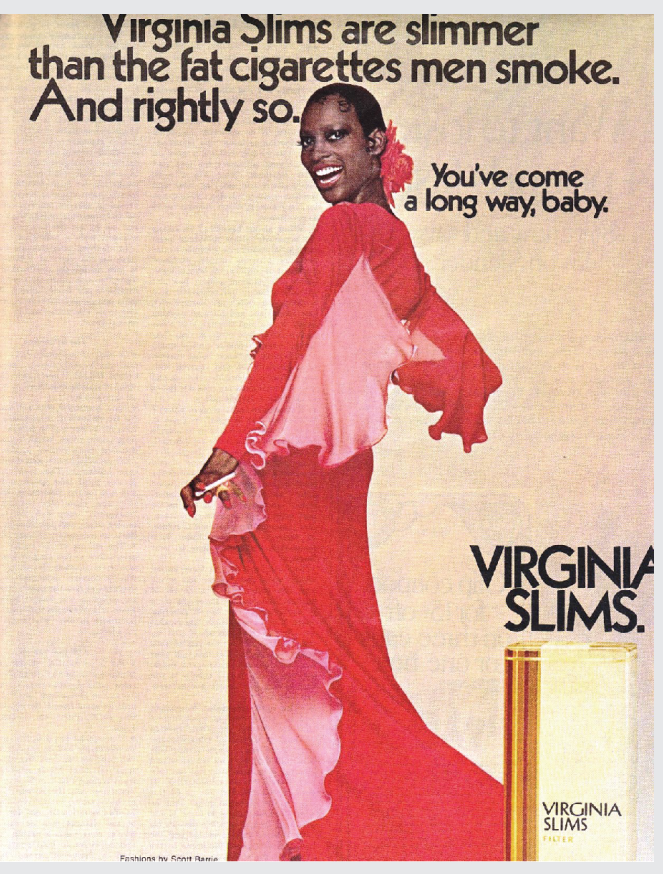

Figure 4. Virginia Slims ad.

http://moazedi.blogspot.com/2014/04/youve-come-

long-way-baby.html

working at useful jobs, the "Baby" ads focused primarily on women's appearances, sacrificing health for beauty. And then there's pregnancy. Smoke these, baby, and don't think about how it might affect your baby's health (Figure 4).

In this ad for Virginia Slims cigarettes, the emphasis is clearly on beauty and weight loss. The message at the top of the ad congratulates the woman for not smoking the "fat" cigarettes that men have to smoke. The round "fat" shape of the letters in the message contrasts with the thinner letters in the name Virginia Slims. The tall slender woman in the ad faces to the left and looks over her shoulder at the viewer, a beaming smile on her unwrinkled face. Her red and pink (naturally) gown flows around her, suggesting elegance. A large bow in the back of her hair completes her ensemble. But where is the cigarette? In her lower left hand, casually pointing up toward her body. While the Marlboro Man actively smokes a cigarette in his ad, the Virginia Slims ads don't show women actually smoking. Perhaps that 


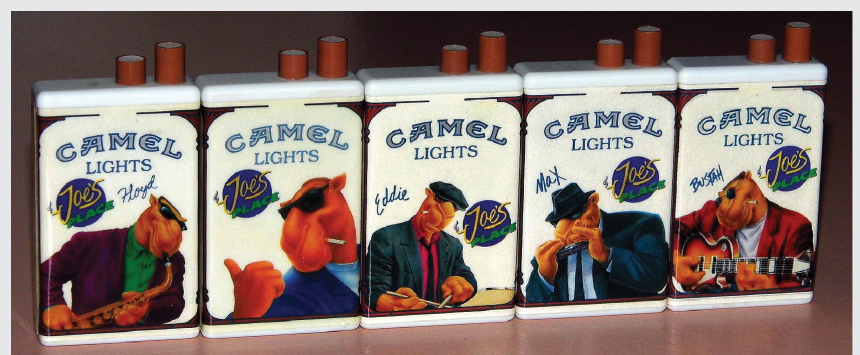

Figure 5. Set of 5 Joe Camel Promotional Cigarette Lighters, Camel Lights Cigarettes.

Joe Camel (officially Old Joe) was the advertising mascot for Camel cigarettes from late 1987 to July 12, 1997. The R. J. Reynolds Tobacco Company, the maker of Camel cigarettes, was alleged to have targeted children with their Joe Camel advertising. 2 August 2014 By Joe Haupt from USA [CC BY 2.0 (https://creativecommons.org/licenses/by/2.0)], via Wikimedia Commons

would be too realistic. Virginia Slims ads attempt to convince women that smoking will increase their independence and confidence, and yet many of the ads show women in provocative poses, and the campaign's jingle condescends to women by calling them "baby."

\section{"You've come a long way, baby \\ To get where you've got to today You've got your own cigarette now, baby You've come a long, long way"6}

Emotional imagery depicting "cool" characters was also important in cigarette advertising that specifically targeted children and teenagers. RJ Reynolds created a series of highly successful advertisements featuring the cartoon character Old Joe Camel (Figure 5). Although company spokespersons denied focusing their ads on young people, research reported in the Journal of the American Medical Association outlined the effects on smoking habits of young people with regard to a specific advertising campaign, stating RJR had been "... far more successful at marketing Camel cigarettes to children than to adults." ${ }^{\text {"Not only }}$ did the ads feature a cartoon character that was as familiar to youngsters as Mickey Mouse, RJR also promoted merchandise giveaways, e.g., tee shirts depicting Old Joe Camel, a Camel baseball cap, a Camel watch. ${ }^{7}$ How ironic that a teenager would wear a shirt that provides free advertising for a product that could eventually kill him.

Which bring us to the current trend in tobacco use: e-cigarettes or vaping. Federal and state laws regulate the sale of e-cigarettes to minors, but controversy still lingers over whether e-cigarettes should be regulated as a tobacco product or as a medical way to stop smoking. Tobacco companies promote e-cigarettes through the same marketing practices used to sell regular tobacco products: ads on billboards and in magazines and other print media. E-cigarettes sponsor sports events and online competitions and appear in computer games. ${ }^{8}$ Although the fluid in e-cigarettes may contain nicotine, flavorings like bubble gum and banana increase the appeal to children and teenagers.

It is imperative, then, to advocate media literacy in an effort to understand how advertisers use targeted strategies to manipulate the emotions of young people. Although state educational standards include media literacy skills, health care personnel can also promote critical thinking skills when discussing the adverse health effects of tobacco use with patients. Recognizing bias and misinformation propaganda in tobacco advertising should allow young people to avoid smoking that first cigarette.

Carl Sagan said it best, "Tobacco is addictive; by many criteria more so than heroin and cocaine. There was a reason people would, as the 1940s ad put it, 'walk a mile for a Camel.' More people have died of tobacco than in all of World War II. According to the World Health Organization, smoking kills three million people every year worldwide. This will rise to ten million annual deaths by 2020 -in part because of a massive advertising campaign to portray smoking as advanced and fashionable to young women in the developing world. Part of the success of the tobacco industry in purveying this brew of addictive poisons can be attributed to widespread unfamiliarity with baloney detection, critical thinking, and the scientific method. Gullibility kills."9

Keywords: cigarettes, media, literacy, advertising 
From: The Department of Internal Medicine at Texas Tech University Health Sciences Center in Lubbock, Texas

Submitted: $7 / 6 / 2018$

Conflicts of interest: none

This work is licensed under a Creative Commons Attribution-ShareAlike 4.0 International License

\section{REFERENCES}

1. Jagger $M$ and Richards K. "[I can't get no] Satisfaction." In Out of our Heads album. Decca Records. Released June 6, 1965.

2. "Basic principles (tools) for media literacy." Albuquerque, NM: New Mexico Media Literacy Project, 2015. http://medialiteracyproject.org/introduction-media-literacy/

3. "Death in the West; Thames-TV anti-smoking documentary." London; Thames Television, 1976. http://sciencecorruption.com/ATN168/00311.html;Retrieved 7/4/2018.
4. Drummond R. "Confessions of a pioneer woman: Marlboro Man." http:// www.thepioneerwoman.com/category/ marlboro-man/

5. "Philip Morris' new Virginia Slims advertising campaign insults and degrades women." Feb. 1, 2001. https://www. tobaccofreekids.org/press-releases/id_0334

6. Moazedi ML. Diversity is beautiful. Posted April 15, 2014.http:// moazedi.blogspot.com/2014/04/youve-come-long-way-baby.html

7. Brody J E. "Smoking among children is linked to cartoon camel in advertisements." The New York Times, Dec. 11, 1991. https://www.nytimes.com/1991/12/11/us/smoking-amongchildren-is-linked-to-cartoon-camel-in-advertisements.html

8. Bauld L, Angus K, de Andrade M. "E-cigarette and marketing; a report commissioned by Public Health England." London: Public Health England, 2014. https://assets. publishing.service.gov.uk/government/uploads/system/ uploads/attachment_data/file/311491/Ecigarette_uptake_ and_marketing.pdf

9. Sagan C. "The fine art of baloney detection." In The DemonHaunted World: Science as a Candle in the Dark. New York; Random House, 1995. 